\title{
Levantamento de requisitos no desenvolvimento de jogos
}

\author{
Airon Wellington Lima dos Santos ${ }^{1}$, Fábio de Jesus Lima Gomes ${ }^{2}$ \\ ${ }^{1}$ Unidade de Tecnologia e Segurança da Informação (UNITEC) \\ Secretaria Estadual de Fazenda - Governo do Piauí - Teresina, PI - Brasil \\ ${ }^{2}$ Departamento de Informação, Ambiente, Saúde e Produção Alimentícia (DIASPA) \\ Instituto Federal do Piauí (IFPI) - Campus Teresina Central - Teresina, PI - Brasil \\ aironwellington@gmail.com, fabiodifpi.edu.br
}

\begin{abstract}
The development of digital games requires the participation of a wide range of area: musician, graphics, programming, history and much others. When analyzing the game create process, find out engineering software application, includes requirements engineering. This paper aims to show the best practices of requirements engineering on the games creation process.
\end{abstract}

Resumo. O desenvolvimento de jogos digitais exige o envolvimento de diversas áreas: música, gráficos, programação, enredo, artes e muitos outros. Ao analisar o processo de criação de jogos pode-se constatar a aplicação de várias práticas de Engenharia de Software (ES), incluindo métodos da engenharia de requisitos (ER). O objetivo desse artigo é mostrar boas práticas da ER no processo de criação de jogos.

\section{Introdução}

Sistemas de software são recursos imprescindíveis nas empresas principalmente pelo papel estratégico em que foram incorporados. Sua construção e manutenção exigem organização e um conjunto de técnicas que quando utilizadas dão uma margem maior ao tempo de vida/sucesso desses softwares. Necessita-se que estes sistemas estejam completamente de acordo com os requisitos listados pelos clientes. Neste contexto, o processo pelo qual os requisitos de um produto de software são coletados, analisados, documentados e gerenciados ao longo do seu ciclo de vida é chamado de Engenharia de Requisitos (ER) [Sommerville 2008].

A ER é aplicada na construção de softwares convencionais, que são aqueles voltados para comércio, indústria, saúde e outros mercados existentes e que partem de um problema inicial até ser transformado em uma solução tecnológica. Entretanto, jogos digitais possuem perspectivas diferentes dos convencionais sistemas de software, apesar de se tratar de um tipo de software, eles são feitos na maioria dos casos para proporcionar diversão, interatividade e lazer. Não existe um problema inicial, a qual eles se propõem a solucionar, há somente a premissa de que devem absorver o máximo de atenção dos seus usuários.

O objetivo deste trabalho é auxiliar os profissionais envolvidos no desenvolvimento de um jogo digital na escolha dos melhores métodos de levantamento de requisitos. A organização do conteúdo abordado neste artigo foi feita da seguinte forma: a seção 2 discorre sobre o desenvolvimento de jogos digitais de uma maneira geral. A seção 3 enfatiza a ER no desenvolvimento de jogos digitais. A seção 4 apresenta os resultados e discussões oriundos deste trabalho e na seção 5 encontra-se uma proposta de trabalhos futuros. 


\section{O Desenvolvimento de Jogos Digitais}

Hoje, o processo de desenvolvimento de jogos digitais não é trivial e deve ser tratado de maneira peculiar, dada a natureza do produto final, a multidisciplinaridade das áreas envolvidas, e ainda o conjunto de ativos que são produzidos durante o processo. [Kanode et al. 2009] definiu 3 fases no processo desenvolvimento de jogos digitais, são elas: pré-produção, produção e teste.

A pré-produção é a fase onde se realiza a concepção de um jogo e de um dos ativos mais importantes, o game design document (GDD). O GDD é um trabalho criativo escrito pelo time de design do jogo e deve ser bem detalhado, mas não necessariamente formal, ou seja, sua estrutura não precisa obedecer a um esqueleto previamente estabelecido ou a uma notação matemática dos programadores. O GDD pode ser considerado um documento de requisitos, cuja estrutura não deve ser rigorosamente padronizada, pois se argumenta que a sua estruturação pode ser altamente prejudicial para a criatividade, e pode prejudicar os elementos intangíveis que criam a experiência agradável para os jogadores.

A produção é onde a maioria dos ativos é criada, incluindo o código do jogo. Esta fase pode ser problemática se o GDD construído na fase anterior não estiver completo e coeso. Na produção, os desenvolvedores podem produzir protótipos, incrementos e/ou iterações do jogo.

A fase de teste é geralmente a última antes de o jogo ser disponibilizado para o mercado. A fase de teste tem como objetivo explorar o máximo dos recursos do jogo. A Figura 1 mostra o gráfico de demonstração do processo de desenvolvimento de jogos com a relação entre o nível de abstração e cada fase do processo.

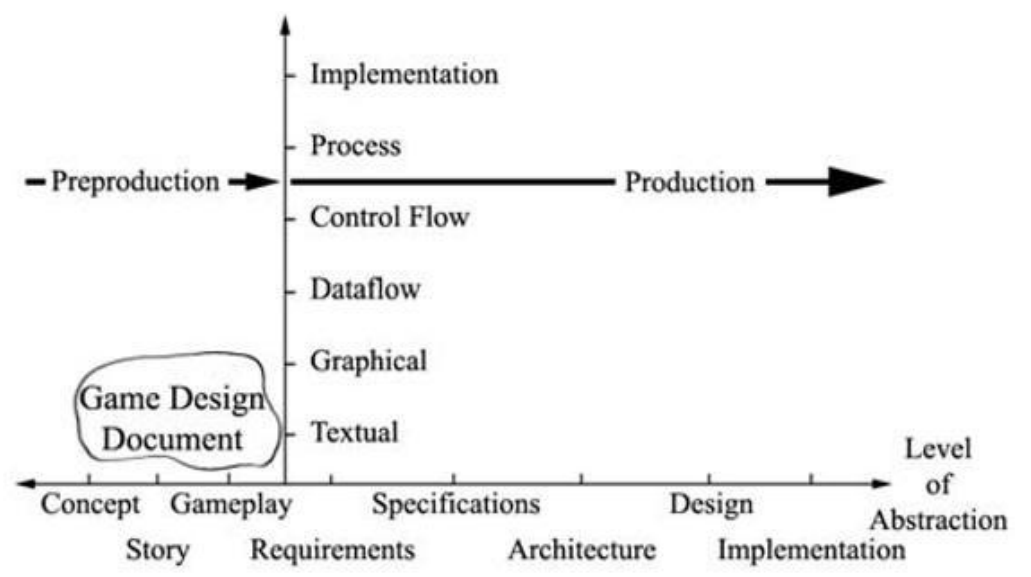

Figura 1. Processo de desenvolvimento de jogos digitais [Callele, et. al 2005]

\section{Engenharia de Requisitos no Desenvolvimento de Jogos Digitais}

A ER é o processo que tem como objetivo criar e manter um documento de requisitos de sistema de software [Sommerville 2008]. Geralmente a ER aborda quatro subprocessos de alto nível: o estudo de viabilidade, obtenção de requisitos, conversão dos requisitos em uma forma padrão e validação desta forma padrão. Para os jogos digitais a atividade de estudo de viabilidade pode ser feita durante a elaboração do projeto, antes de iniciar a atividade propriamente dita de desenvolvimento do jogo, durante a elaboração do projeto em nível de gerenciamento.

Assim que o estudo de viabilidade estiver completo e o projeto possuir a aprovação dos gerentes começa-se a fase de pré-produção. Ao final desta fase deve ser disponibilizado o documento de requisitos e o GDD. Os engenheiros de sistemas, analistas e todos os interessados no projeto devem participar da obtenção de requisitos. 
No desenvolvimento de jogos digitais, principalmente na fase de pré-produção é confeccionada a especificação de requisitos, documento cujo objetivo principal é elencar requisitos funcionais (funcionalidade do sistema) e requisitos não funcionais (comportamento do sistema, por exemplo: tempo de resposta, disponibilidade, entretenimento) e requisitos de domínio (comportamento do sistema relativo à área em que está relacionado, por exemplo, movimentos de um personagem dentro do jogo). Além de conter requisitos, o documento deve ser estruturado de tal forma que os desenvolvedores do sistema possam simplesmente preocupar-se com a programação.

A transformação do GDD em especificação de requisitos é considerada a fase mais complexa durante o desenvolvimento do jogo uma vez que não há técnicas estabelecidas para elicitação de requisitos emocionais. Outro fator importante ao elaborar o documento de requisitos é que utilizar feedbacks contínuos e fazer uso de engenharia de maneira proativa no desenvolvimento de jogos pode prover retornos da produção para pré-produção em resposta da otimização de versões iniciais de documentação da pré-produção.

Dentro do processo de obtenção de requisitos deve-se (1) identificar os interessados, (2) reconhecer o ponto de vista e (3) trabalhar em busca de colaboração. [Pressman 2012] defende que são essas as etapas necessárias para estabelecer as bases para um entendimento dos requisitos de software e para que o projeto avance na direção de uma solução bem sucedida.

Neste intuito, é possível realizar workshops entre as equipes e pedir para que um usuário final (jogador) do sistema seja o facilitador. O workshop tem o objetivo de acionar o trabalho em equipe. Uma técnica bastante utilizada dentro do workshop é o brainstorming. O brainstorming é uma técnica que consiste em uma ou várias reuniões onde os participantes podem sugerir e explorar ideias. Ao final do workshop são produzidos documentos que refletem os requisitos e decisões tomadas sobre o jogo.

Atualmente, jogos digitais utilizam diversos tipos de tecnologias de terceiros, como engines ${ }^{l}$, animações de personagens, e outros tipos de componentes. Esses tipos de recursos facilitam a construção de protótipos e diminuem custos. Com isso é muito comum utilizar a prototipagem no desenvolvimento de jogos digitais. A prototipagem tem por objetivo explorar aspectos críticos dos requisitos de um produto, implementando de forma rápida um pequeno subconjunto de funcionalidades.

Outra técnica que pode ser utilizada para capturar requisitos é o JAD (Joint Application Design). O JAD é uma técnica para promover cooperação, entendimento e trabalho em grupo entre os usuários desenvolvedores. O JAD facilita a criação de uma visão compartilhada do que o produto de software deve ser. Através da sua utilização os desenvolvedores ajudam os usuários a formular problemas e explorar soluções.

É importante ressaltar que as técnicas aqui apresentadas são aplicadas na fase de elaboração do documento de requisitos, ou seja, o processo de criação do GDD. Os responsáveis por este processo são os artistas e designers. Uma das fases mais críticas de muitos projetos é a transição do GDD para o documento de requisitos, pois os erros cometidos nesta transição podem implicar no fracasso da implementação do projeto.

\section{Resultados e Discussões}

Com base nas técnicas de ER descritas nos trabalhos expostos ao longo deste artigo concluímos que as melhores práticas para elencar requisitos de jogos digitais são

\footnotetext{
1 Uma engine é uma biblioteca com um pacote de funcionalidades que são disponibilizadas para facilitar o desenvolvimento de um jogo, fornecendo um bom visual e diversos itens da jogabilidade, tais como, o sistema de colisão entre personagens e objetos e a inteligência artificial de inimigos ou parceiros.
} 
aquelas em que a equipe multidisciplinar consegue mitigar a disparidade de desenvolvimento de cada subárea envolvida no processo de criação de jogos de vídeo.

Algumas práticas de levantamento de requisitos para jogos digitais são: JAD, prototipagem, brainstorming e workshops, uma vez que conduzem os desenvolvedores à cooperação na fase de produção do GDD e especificação de requisitos.

É importante ressaltar que apesar das técnicas mencionadas serem consideradas práticas adequadas no processo de criação de ativos na fase de pré-produção de jogos, elas não estabelecem um protocolo que atenda o processo como um todo, uma vez que a criação de jogos envolve também requisitos não funcionais como jogabilidade, entretenimento e diversão.

\section{Trabalhos Futuros}

As limitações referentes ao presente estudo deixam em aberto a necessidade de formalizar as técnicas apresentadas no desenvolvimento de jogos digitais. É difícil definir qual a melhor técnica a se utilizar, precisando-se realizar uma análise minuciosa de cada uma delas, conhecendo suas limitações e vantagens. Idealmente, necessita-se aplicar essas técnicas em empresas profissionais de desenvolvimento de jogos digitais para avaliar os resultados obtidos com o uso de cada uma.

Em suma, a perspectiva de trabalho futuro está relacionada a explorar em detalhes as técnicas aqui apresentadas através da criação de um questionário online destinado a empresas de desenvolvimento de jogos digitais, onde os usuários (empresas) devem informar quais técnicas vem utilizando no desenvolvimento de jogos e como é o passo-a-passo de aplicação da técnica informada na sua empresa. As respostas obtidas com o questionário servirão como indicadores de qualidade para as práticas que mais são utilizadas, e ao mesmo tempo servirão de apoio para aqueles que pretendem aderir ao uso das melhores práticas e desejam saber como utilizá-las.

Esses indicadores e informações de apoio serão baseados nos resultados obtidos por meio das empresas e assim teremos condições de nortear os interessados neste assunto de forma mais segura e precisa sobre como fazer o levantamento de requisitos no processo de desenvolvimento de jogos digitais.

\section{Agradecimentos}

Agradecemos à Fundação de Amparo à Pesquisa do Estado do Piauí (FAPEPI) pelo auxílio financeiro concedido para a apresentação deste trabalho no evento.

\section{Referências}

CALLELE, D.; NEUFELD, E.; SCHNEIDER, K. (2005) Requirements Engineering and the Creative Process in the Video Game Industry. In: 13th IEEE International Conference on Requirements Engineering, Washington, DC, USA. Proceedings: IEEE Computer Society, 2005. Disponível em: $<$ http://ieeexplore.ieee.org/stamp/stamp.jsp?arnumber=1531045>. Acesso em: 30 ago 2016.

KANODE, C. M.; HADDAD, H. M. (2009) Software Engineering Challenges in Game Development. In: 6th IEEE International Conference on Information Technology: New Generations, Las Vegas, USA. Proceedings: IEEE Computer Society, 2009. Disponível

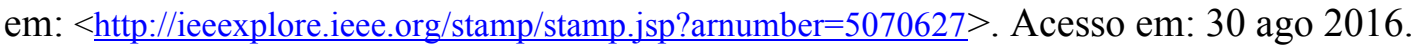

PRESSMAN, R.S.; MAXIM, B. R. (2016) Engenharia de Software: Uma abordagem Profissional. $6^{\mathrm{a}}$. Edição. Editora McGraw Hill - Bookman.

SOMMERVILLE, I. (2011) Engenharia de software. $9^{a}$ edição. Editora Pearson. 